ISSN 0103-7013

Psicol. Argum., Curitiba, v. 29, n. 64, p. 101-108 jan./mar. 2011

Licenciado sob uma Licença Creative Commons

(c) $(9)$

\title{
Costurando saúde: Possibilidades de integração por meio da confecção de bonecos(as) de pano em um CAPS infantil
}

\author{
Sewing health: Possibilities of integration through \\ rag dolls making in a child psychosocial care centers \\ Valéri Pereira Camargo ${ }^{[\mathrm{a}]}$, Marisangela Spolaôr Lena ${ }^{[\mathrm{b}]}$, \\ Hericka Zogbi Jorge Dias ${ }^{[\mathrm{c}]}$, Adriane Rubio Roso ${ }^{[\mathrm{d}]}$
}

Psicóloga, mestranda em Psicologia na Universidade Federal de Santa Maria (UFSM), bolsista CAPES/REUNI, Santa Maria, RS - Brasil, e-mail: valericamargo@yahoo.com.br

[b] Psicóloga, mestranda em Psicologia na Universidade Federal de Santa Maria (UFSM), Santa Maria, RS - Brasil, e-mail: marisangelaslena@yahoo.com.br

Psicóloga, Doutora em Psicologia, professora adjunta do departamento de Psicologia da Universidade Federal de Santa Maria (UFSM), Santa Maria, RS - Brasil, e-mail: ckzogbi@gmail.com

Psicóloga, Doutora em Psicologia, professora adjunta do departamento de Psicologia da Universidade Federal de Santa Maria (UFSM), Santa Maria, RS - Brasil, e-mail: psicologia.ufsm@gmail.com

\section{Resumo}

O objetivo deste estudo é apresentar as atividades desenvolvidas em um centro de atenção psicossocial para crianças (Centro de Atenção Psicossocial - CAPS), em uma cidade do interior do Estado do Rio Grande do Sul, Brasil, durante o verão de 2009. Baseando-se em alguns princípios da arteterapia e em conceitos básicos da teoria psicanalítica winnicottiana, oficinas foram delineadas para promover saúde entre pacientes infantis e para fortalecer uma abordagem multidisciplinar de cuidados em saúde. Nos encontros do grupo, cada participante (paciente, familiar e cuidador da saúde) desenhou e costurou um(a) boneco(a) de pano. Os participantes eram estimulados a falar sobre seus sentimentos durante o processo terapêutico. A confecção dos(as) bonecos(as) não somente propiciou um novo ensaio da experiência transicional, mas, acima de tudo, favoreceu um espaço sem estigmatização, no qual os participantes puderam reconhecer-se como sujeitos criativos e capazes de adquirir competências psicológicas e culturais.

Palavras-chave: Psicologia de grupo. Arteterapia. Winnicott. Centro de Atenção Psicossocial (CAPS). 


\begin{abstract}
The aim of this study is to present the activities developed at a community mental health services for children (Psychosocial Care Centers - CAPS) in a median-size city in the State of Rio Grande do Sul, Brazil, during the 2009 summer. Grounded on some principles of art therapy and basic concepts of Winnicott's psychoanalysis theory, workshops were outlined to promote health among infant patients and to enhance a multidisciplinary health care approach. In the group encounters each participant (patients, family members and health care workers) designed and sewed a ragdoll. The participants were stimulated to talk about their feelings during the therapeutic process. The manufacturing of rag dolls not only promote a new rehearsal of the transitional experience, but, most of all, it favored a non-stigmatized space whereas the participants could recognize themselves as creative subjects and capable of acquiring psychological and cultural competences.
\end{abstract}

Keywords: Group psychology. Art therapy. Winnicott. Psychosocial Care Centers - CAPS.

\section{Introdução}

\section{Como estranhas lembranças de outras vidas, que outros viveram num estranho mundo, quantas coisas perdidas e esquecidas no teu baú de espantos... Bem no fundo, \\ uma boneca toda estraçalhada! (isto não são brinquedos de menino... alguma coisa deve estar errada) mas o teu coração em desatino \\ te traz de súbito uma idéia louca: é ela. sim! Só pode ser aquela a jamais esquecida Bem-Amada.}

E, em vão tentas lembrar o nome dela... e em vão ela te fita...e a sua boca tenta sorrir-te mas está quebrada!

$$
\text { (Mario Quintana, O baû) }
$$

Crianças em tratamento nos serviços de atenção psicossocial podem ser vistas - e erroneamente compreendidas - como crianças quebradas. Em termos de desenvolvimento emocional, sabemos que a integração do ego e a diferenciação entre objetos internos e externos se dão, segundo Winnicott(1983), por meio de muitos elementos, desde a maternagem, as possibilidades do ambiente e, aqui, com especial atenção, os objetos transicionais.

Uma criança dificilmente esquece seu primeiro(a) boneco(a), ou o seu boneco(a) preferida(o). Ele(a) é, certamente, o primeiro objeto transicional que existe para o sujeito em construção, menino ou menina. A psicologia reconhece a importância desse objeto transicional desde Winnicott e, de acordo com ele, o(a) boneco(a) enquanto objeto transicional representa o seio, ou o objeto da primeira relação, e entre outras funções ele complementa o bolding, que é baseado na experiência da confiabilidade essencial à saúde da criança (Winnicott, 1975, 2005).

A psicologia, a partir de suas diversas teorias e métodos, pode contribuir para a (re)construção da capacidade da criança de confiar e de manter o estágio do "eu sou" descrito por Winnicott (2005), ou seja, de desenvolver seu processo de singularização (Guattari \& Rolnik, 1986) ou diferenciação rumo à independência (Winnicott, 1983). Dentre essas teorias e métodos, encontramos a arteterapia e a perspectiva winnicottiana, que valorizam o brincar no processo terapêutico.

A arteterapia, segundo a Associação Americana de Arteterapia-AATA (2009), é uma profissão da saúde mental que utiliza o processo criativo de fazer arte para melhorar o bem-estar físico, mental e emocional dos indivíduos de todas as idades. É baseada na crença de que o processo criativo envolvido na autoexpressão artística ajuda as pessoas a resolver conflitos e problemas; desenvolver habilidades interpessoais; gerenciarcomportamentos; reduzir estresse; aumentar a autoestima e a autoconsciência; e alcançar insight. A arteterapia integra os campos do desenvolvimento humano, das artes visuais (desenho, pintura, escultura e outras formas de arte) e o processo criativo com os modelos de aconselhamento e psicoterapia. ${ }^{1}$

1 Tradução livre das autoras. 
Por meio da arte, a pessoa aprende a lidar com seus sentimentos, com suas emoções, sensações, pensamentos, acabando por concretizá-los em símbolos, formando, assim, o seu estilo próprio de expressão artística. Nisso, a pessoa descobre os seus potenciais não somente artísticos, mas também da sua vida interior. Nesse percurso, o papel do terapeuta é propiciar estímulos ao paciente para que ele possa criar elementos para a construção de sua singularidade, observando sempre as suas atividades e as suas expressões verbais e não verbais na finalização de uma obra única (Saviani, 2004).

A perspectiva winnicotiana volta-se para o desenvolvimento de uma teoria da cultura, a partir dos estudos sobre as relações, entre os fenômenos transicionais e o brincar. As características do atendimento fogem ao padrão clássico do setting, uma vez que existe a disponibilidade do terapeuta em adaptar-se às necessidades do paciente (Polity, 1998), e é sobre essa possibilidade que este trabalho se apoia.

Este artigo visa a apresentar os resultados da atividade de confecção de bonecos(as) desenvolvida no espaço de oficinas terapêuticas, realizadas em um Centro de Atendimento Psicossocial Infantil (CAPS). ${ }^{2}$ Como salienta Winnicott (1975, p. 80), é justamente no "brincar, e somente no brincar, que o indivíduo criança, ou adulto, pode ser criativo e utilizar sua personalidade integral: e é somente sendo criativo que o indivíduo descobre o eu (self)".

A execução de oficinas mostra-se pertinente para uma nova forma de tratamento à medida que proporciona um espaço terapêutico diferenciado e onde se torna possível integrar, em uma mesma atividade, pacientes do serviço de saúde mental, familiares, funcionários e demais membros da comunidade. Assim, a oficina de confecção de bonecos(as) de panos realizada visou, por meio da arte, a proporcionar integração por intermédio do trabalho com questões relativas à autopercepção e à constituição corporal.

\section{O papel da oficina na construçáo da saúde}

As oficinas, como salientou Galleti (citado por Lima, 2004), não são definidas por um modelo único de intervenção e existência homogênea, mas são compostas pordiversas naturezas, numa multiplicidade de formas, processos elinguagens. Tratando-se de uma oficina de bonecos(as) de pano, além da integração dos participantes, há a relação com a própria criação: o(a) boneco(a) ganha vida pela voz daquele que o criou e, ao dizer como é o(a) boneco(a) - o que o faz feliz e triste e o que sente -, o seu construtor pode falar de si, do que faz ele feliz ou triste, do que ele sente e de como ele é, numa espécie de confissão menos angustiante. $\mathrm{O}(\mathrm{a})$ boneco(a), ainda, pode se relacionar com o seu criador por meio do brincar, podendo ser um meio pelo qual se busca uma unificação geral da personalidade (Winnicott, 1982), ou seja, ao se criar um(a) boneco(a), pode-se recriar o self.

Corroborando os princípios do CAPS, a execução de uma oficina artística vem a ser um instrumento terapêutico capaz de proporcionar, além da saúde mental, um espaço de convivência e integração de pacientes com a sociedade - e de integração do próprio paciente - e, principalmente, a capacidade de ser um espaço desestigmatizador, onde os participantes podem se reconhecer como sujeitos criativos, capazes de adquirir competências e construir objetos.

\section{Método de construçáo de bonecas: Táticas de construçáo de singularidades}

Foram realizados, na oficina, quatro encontros com duração de duas horas cada e periodicidade quinzenal no período de janeiro a março de 2009. Além das coordenadoras das oficinas, participaram doze pessoas, sendo seis pacientes do CAPS, uma profissional da saúde do CAPS, uma adolescente da comunidade, três mães e uma irmã de paciente do CAPS. Não foi feita restrição de idade, tendo

2 O Centro de Atendimento Psicossocial Infantil (CAPS) é um serviço originado com o advento da reforma psiquiátrica e que visa à substituição do asilamento por tratamentos mais sociabilizantes, busca fornecer assistência aos pacientes, respeitando-os social e civilmente e não os isolando de sua família e da sociedade, proporcionando o resgate de sua cidadania (Scharanck \& Oischowski, 2008). 
participado crianças de 7 anos até adultos de 50 anos. Os encontros foram facilitados por duas acadêmicas de psicologia, supervisionadas no local por uma psicóloga do CAPS e academicamente por duas professoras da UFSM.

Iniciamos por ensinar técnicas de confecção - molde, recorte, cosimento, etc - para que construíssem seus próprios bonecos(as), o que vai ao encontro da proposta winnicottiana de "brincar" junto com o paciente: a psicoterapia como lugar no encontro de duas áreas do brincar: uma do paciente, outra do terapeuta.

Quanto à estruturação dos encontros, excetuando o primeiro encontro, os demais foram livres para a construção. O primeiro encontro foi estruturado com a apresentação dos participantes e exposição das motivações para participar da oficina, criação mental do boneco, desenho do boneco imaginado, apresentação do boneco para os demais integrantes e início da confecção em pano. Integrantes novos no grupo foram admitidos quando esse já estava em andamento, assim, a estrutura do primeiro encontro era realizada com os novos integrantes.

Para os encontros, foram utilizados materiais de artes, reciclagem e artigos de costura, cujos custos foram divididos entre o CAPS e as facilitadoras da oficina. Foi definido pelo CAPS que todo material produzido pelos integrantes do grupo pertenceria a eles e que, ao final das atividades, as produções pudessem ser mostradas em uma exposição interna.

\section{Arremate: Construindo o "eu sou" por meio de oficinas}

Os funcionários da instituição, quando convidados a participar da oficina de bonecos, questionaram as oficinas enquanto possíveis agentes terapêuticos. Além disso, o receio de estar em um mesmo grupo que pacientes e familiares pode ter gerado fantasias quanto aos limites do self. A mistura de pacientes e funcionários poderia levar, no imaginário do funcionário, à descaracterização de sua função, gerando uma ameaça ao seu "eu sou".

Uma das falas no primeiro encontro é ilustrativa: "por que en fui me inscrever numa oficina de bonecos de pano se eu nem sei costurar?". Ainda, a participante comentou sobre a dificuldade de estar no grupo em outro papel, falando para uma das facilitadoras: "eu sinto que teu olhar me dir, far! E a gente num grupo sempre faz assim com os participantes, mas como é difícil simplesmente fazer".

Possivelmente, o reconhecimento do local do grupo como um espaço diferente, voltado para a arte, criatividade e livre construção, fez com que mais pessoas se interessassem em constituí-lo, tendo as vagas sido preenchidas a partir do segundo dia de oficina. Ao que pareceu, as oficinas começaram a se constituir como um espaço potencial, no qual, argumentaria Polity (2002), o "eu" em vez de combater o "não eu", aceita a derrota da onipotência como instrumento de administração do mundo.

Participaram do primeiro encontro uma mulher adulta e duas adolescentes. $O$ fato de aparecerem, inicialmente, apenas mulheres não nos surpreendeu. Embora muitas pessoas tenham em seu "baú de espantos" uma boneca toda estraçalhada-que não é brinquedo de menino, mas jamais é esquecida -, na cultura brasileira bonecas são artefatos divisórios de gênero. De fato, durante os quatro encontros somente dois meninos participaram das atividades, um deles optou ainda por fazer uma máscara de monstro e uma pipa, brinquedos tipicamente masculinos.

$\mathrm{Na}$ primeira etapa, logo que as integrantes chegaram à sala e se acomodaram nos bancos, foi realizada a exposição dos objetivos da oficina e o que seria realizado nesse espaço. Após o momento de timidez inicial, cada participante se apresentou com nome, idade e o que esperava da oficina. A fala das três participantes trouxe a vontade de conhecer a técnica de confecção dos bonecos e dois disseram que não sabiam costurar e que a oficina seria a oportunidade para aprender coisas novas, além de conhecer novas pessoas. Pôde-se observar, então, que essa atividade de costura iria além da mera construção técnica de um objeto; ela se constituiria num espaço potencial, no qual o mundo interno e o mundo externo se entrelaçariam, propiciando o fortalecimento dos vínculos e do florescimento da criatividade.

Quando as participantes e as monitoras terminaram de se apresentar, foi iniciado o processo de criação dos(as) bonecos(as) - a criação mental. Estimulados por questionamentos como "que tamanho o boneco tem?”, "como é o cabelo dele?", "ele se parece com alguém?”, "o que ele gosta de fazer?”, “o que o faz feliz?”, “o que o deixa triste?”, "qual é o nome dele?", o grupo foi pensando o seu boneco e construindo-o.

A segunda etapa da criação foi a do desenho, em que as participantes colocaram no papel o que 
haviam imaginado sobre o seu boneco. Essa etapa despertou na adulta integrante do grupo entusiasmo, ao que se ouviu "faria tanto tempo que não desenhava que já nem lembrava mais como era. Vou pegar lápis de cores para colorir porque me empolguei'. Logo, os desenhos foram apresentados ao grupo e as características do(a) boneco(a) explanadas. Nessa fase, percebeu-se que as participantes se permitiram falar delas próprias e de suas dificuldades pessoais por meio do objeto, como a boneca - desenhada por uma participante com diagnóstico de depressão - que não tem família e que se mostra feliz na frente dos outros, mas é mesmo muito triste e a boneca magrinha, loira e acinturada, desenhada por uma adolescente que posteriormente se soube que estava no CAPS em razão de uma tentativa de suicídio, aparentemente motivada pela não aceitação de sua imagem corporal.

Durante o período do encontro, palavras como "gestação" e "nascimento" foram frequentes para referenciar a confecção dos(as) bonecos(as), o que mostrou a implicação das integrantes em fazer seus objetos, como se o(a) boneco(a) ao ser criado(a) estivesse adquirindo vida. Ao mesmo tempo em que elas gestam, elas nascem; e com isso são, ao mesmo tempo, produtoras e produtos da história. E nesse viver criativo "descobrimos que aquilo que fazemos fortalece o sentimento de que estamos vivos, de que somos nós mesmos" (Winnicott, 2005, p. 28).

A realização da delimitação corporal do(a) boneco(a) foi também um momento importante, no qual uma integrante do grupo desejava desenhar sua boneca, que era ela própria com cinco anos de idade, em tamanho real e não encontrava pano em que coubesse inteira. Já outra adolescente fez sua boneca tão pequena que não se conseguia colocar enchimento.

Aqui fica clara a confusão entre o real e o ilusório, entre o que é o meu self bebê e o meu self mais maduro. Entretanto, ambas as participantes do grupo conseguiram encontrar saídas para seus problemas, com uma aceitando fazer sua boneca alguns centímetros menor e a costurando em casa - já que visivelmente o tempo para finalizá-la seria insuficiente no grupo-e com a outra decidindo fazer um chaveiro de sua pequena boneca.

Logo após terem aprendido a costurar, as integrantes diziam "como é fácil" e "quem diria eu costurando", fato esse que mostra a surpresa das próprias integrantes em adquirirem uma habilidade que antes consideravam improvável de ser realizada: a construção e o reconhecimento de si mesmas. Com a proximidade do término do encontro e a necessidade de guardar o material utilizado, foi visível a maneira cuidadosa e diferenciada com que as participantes tratavam suas criações. Cada boneco foi embalado com cuidado e delicadeza, como se pudesse se machucar se fosse tratado de outra forma.

No segundo dia de oficina, já com dez participantes, a apresentação pessoal foi feita e nesse momento se pode notar o quanto seria desafiador o encontro, já que muitos participantes interrompiam a fala de outros durante a apresentação. Uma mãe participante não conseguia passar a palavra aos demais integrantes e ainda uma adolescente tentou se esconder embaixo da mesa ao sentir-se observada pelos colegas de grupo.

Com maior número de participantes e pela visível variação de idade entre os componentes (o mais novo era um menino de 7 anos e a mais velha, uma mãe de uma paciente do CAPS de 50 anos), a oficina foi bastante intensa e alguns comportamentos estereotipados de pacientes, como a tentativa de isolamento de alguns e os pedidos de um integrante para que uma das facilitadoras lhe desse atenção exclusiva e fizesse com ele uma pipa, puderam existir em um mesmo espaço, onde eles não foram julgados por suas diferenças.

Para o terceiro encontro, aceitou-se a participação de mais uma mãe e seu filho, paciente do CAPS, apesar de as dez vagas preestabelecidas terem sido preenchidas. Por conta da ausência de seis participantes que haviam colocado seu nome na lista, a oficina contou com seis integrantes nesse dia. Pôde-se observar a relação estabelecida entre os novos integrantes do grupo: mãe e filho. A mãe, sob o argumento de auxiliar o menino de 8 anos, desenhou o boneco para ele e o ensinou a costurar. O menino, entretanto, não conseguia finalizar os pontos no tecido e resmungava reclamando das imperfeições e do tamanho grande do boneco feito pela mãe. $\mathrm{Na}$ metade do encontro, o menino tomou a iniciativa de fazer o desenho de seu próprio boneco e daí sim conseguiu costurá-lo com eficiência.

A mãe disse, ainda, que daria ao boneco o mesmo nome do filho, fato esse que gerou revolta no menino, que disse: "não quero que teu boneco tenha meи nome" e uma das monitoras indagou brincando "tu não quer ser o boneco da tua mãe?" e ele respondeu prontamente "não, ela que arrume outro nome". A mãe sorriu parecendo incompreender a resposta aversiva 
do menino. Todavia, para o filho parece ter sido apontada a importância do "eu sou”, que não é um reflexo da percepção materna, fato que, provavelmente, o fez encarar o boneco desenhado pela mãe como imperfeito e desproporcional.

Nesse encontro, a fase de costura já estava bem avançada para os participantes assíduos e duas das integrantes já estavam no processo de enchimento dos bonecos. Uma participante, entretanto, chegou a se dirigir para uma das facilitadoras pedindo auxílio para a costura. Ela estava nervosa porque aprendera a costurar o corpo em linha reta e o braço não era reto, era "pro lado". Quando a monitora sugeriu à adolescente que virasse $\mathrm{O}$ boneco, pois o braço ficaria para cima e ela saberia costurar ele reto, a expressão da moça foi de surpresa e entusiasmo, talvez por perceber que um fator que considerava desafiador ou impossível pode ser solucionado e agora ela poderia costurar o seu boneco - bastava olhar "o problema" sob uma nova perspectiva.

A reação às próprias criações foi um fator evidentemente relevante, muitos participantes demonstraram surpresa pelo que foi possível fazer nos encontros dizendo: "nem parece que fui eu que fir"; ou "que bonito ficou o boneco"; ou mesmo aparentando desprezo pelo trabalho feito, como uma integrante que disse várias vezes que colocaria sua boneca no lixo - apesar de nunca tê-lo feito; ou mesmo pedindo uma confirmação para as facilitadoras e outros componentes do grupo, pedindo para dizerem como está o seu trabalho: "é assim?", "está ficando bonito?", "está parecido comigo?".

No quarto e último encontro, o número de integrantes foi de apenas três: uma funcionária, uma paciente do CAPS e uma monitora. Uma das integrantes deixou de participar por ocasião de sua alta do serviço. Quanto aos participantes que faltaram nesses dias, acredita-se que a dificuldade de assimilar o final da oficina possa tê-los afastado justamente do último encontro.

A funcionária participante da oficina chegou ao último encontro com sua boneca praticamente pronta, já que ela disse ocupar os horários de intervalo do serviço para costurá-la e levando-a, ainda, para casa a fim de colocar um enchimento colorido que possuía. A adolescente que também compareceu ao grupo ainda estava na fase de costura, já que ia fazendo os pontos e pondo o enchimento ao mesmo tempo, atividade que lhe ocupou mais tempo. A ambiguidade da relação dessa integrante com sua boneca foi um fato interessante de ser observado no encontro: ao mesmo tempo em que investia na boneca, pedia auxílio para fazê-la, dizia que estava feia e que a jogaria fora. A adolescente disse muitas vezes: "fiz uma coisa feia, não quero! Vou pôr fora?". Ao final ela disse: "então en vou dar ela pra minha mãe".

A adolescente referida participou de todos os encontros da oficina e foram perceptíveis as diferenças em seu comportamento do princípio - quando desejava se esconder embaixo da mesa, fugia do espelho e não falava com os demais integrantes - para o final - quando já podia se expressar em grupo e falar das coisas que gostava e não gostava. Ela não conseguiu finalizar seu trabalho no último dia de oficina, mas escolheu as cores para as roupas e a cor do cabelo e continua confeccionando sua boneca, ainda sem nome, durante outras oficinas realizadas no CAPS e, apesar das constantes ameaças, não a jogou fora.

Consideramos que as perguntas ("está ficando bonito?") e as ameaças ("voujogarfora") surgem da necessidade de avaliar se o holding suporta a destrutividade-jogar a boneca no lixo. As facilitadoras, ao propiciarem um segurar confiável, possibilitam que os participantes do grupo cresçam.

\section{Discussão}

A oficina de bonecos se mostrou um espaço diferenciado de integração entre pacientes e comunidade, onde todos compartilharam do não saber inicial - exposto pela pergunta "como se far. um boneco?" - para o saber originado de uma produção conjunta: "o meu boneco se far assim". Foi um local onde as normas existentes não esmagaram a capacidade criadora e onde foi possível fazer o que havia se imaginado como boneco(a), mesmo que este se apresente como um chaveiro ou uma máscara. O que se considerou foi o significado que o construtor atribuiu à sua criação.

Cada boneco(a) foi uma criação espontânea de cada participante, já que não foram dados moldes, formas ou regras para a confecção, pelo contrário, fornecemos uma gama de materiais possíveis e atendeu-se aos pedidos dos pacientes de auxiliá-los a cortar pano ou ensinar a suturar tecidos, mas sem que tal ajuda interviesse no seu 
processo criativo: cada boneco(a), assim como cada construtor, tornou-se único - singular!

A atividade foi relevante por apresentar ao CAPS uma nova forma de atuação e de visão acerca dos pacientes, como sujeitos com capacidade criadora, muito além de um sujeito doente. O projeto foi importante, ainda, por proporcionar aos integrantes um espaço onde questões pessoais foram trabalhadas de forma humana e facilitadas pelo fazer artístico, já que muitos integrantes que não falavam muito de si puderam, por meio de seus bonecos(as), mostrar-se e também escutarse, percebendo suas capacidades e dificuldades e podendo, então, trabalhar com elas.

A tarefa foi igualmente uma experiência singular para as facilitadoras, que por vezes sentiram-se desafiadas, solicitadas em demasia e até impotentes. O sentimento de impotência foi despertado logo no primeiro encontro, quando o número de participantes foi bem abaixo do que se esperava. Talvez a deficiente divulgação tenha sido a principal causa, mas trabalhar numa oficina com a sensação de que esta não estava sendo aceita foi uma tarefa difícil.

Logo, com a oficina em andamento e as vagas preenchidas, o principal desafio foi o de manter os integrantes na atividade, pois alguns participaram de somente um encontro. Apesar de a proposta inicial da oficina estar centrada no processo de criação e importância do exercício da confecção, permitir que os integrantes saíssem da oficina com seus bonecos não arrematados e sem enchimento foi angustiante, porém, necessário, como os fluxos das atividades propostas para grupos.

A cobrança por resultados e participação massiva foi outra dificuldade enfrentada. Alguns técnicos da instituição, ao se referir à oficina durante as reuniões gerais, demonstravam incredulidade quanto aos possíveis benefícios desta aos integrantes e, principalmente no início da oficina, quando o número de vagas não foi preenchido, houve cobrança sobre a "não aceitação da atividade" em razão da baixa adesão. No entanto, não temos certeza de que um elevado número de participantes garantiria a eficácia e a importância do trabalho.

A relevância da oficina, no entanto, foi sendo construída pelos seus próprios integrantes, que optavam por participar dela pelos mais variados motivos: porque queriam aprender a costurar, queriam uma boneca nova, estavam na sala de espera sem fazer nada. Assim, com aparente despretensão, a oficina de bonecos foi conquistando espaço dentre as demais atividades do CAPS e se caracterizando como uma atividade inédita, de participação voluntária e integrativa, um verdadeiro espaço potencial.

Acredita-se que essa experiência realizada no CAPS possa estimular novos projetos criativos que se utilizem de artifícios diversos para buscar a integração social dos pacientes, desestigmatizar o CAPS e proporcionar dentro desse serviço um espaço não somente para o tratamento de patologias, mas também um local para se trabalhar com a saúde mental em seus diferentes âmbitos e para diversos públicos, como pacientes, familiares, comunidade e também funcionários.

\section{Referências}

American Art Therapy Association - AATA. (2009). About Art Therapy Reston, VA: The American Art Therapy Association. Retrieved Jan. 3, 2009, from http://www.arttherapy.org/aboutart.htm

Guattari, F., \& Rolnik, S. (1986). Cartografias do desejo. Petrópolis: Vozes.

Lima, E. A. (2004). Oficinas, laboratórios, ateliês, grupos de atividades: Dispositivos para uma clínica atravessada pela criação. In C. Costa \& A. Figueiredo. Oficinas terapêuticas em saúde mental: Sujeito, produção e cidadania (pp. 59-81). Rio de Janeiro: Contra Capa Livraria.

Polity, E. (1998). Uma leitura Winnicottiana na terapia familiar. Trabalho apresentado no Encontro Internacional de Família e Psicanálise, Universidade São Marcos, Recuperado em 7 mar. 2009, em http://www.winnicott.com.br/texto_detalhe. asp?txi_ID $=43$

Polity, E. (2002). Algumas considerações sobre o espaço potencial. Psicologia: Teoria e Prática, 4(1), 21-28, Recuperado em 4 nov. 2008, em http://www.mackenzie.br/fileadmin/Editora/Revista_Psicologia/ Teoria_e_Pratica_Volume_4_-_Numero_1/v4n1_ art2.pdf

Quintana, M. (1980). Esconderijos do tempo. Porto Alegre: L\&PM. 
Saviani, I. (2004). Ateliê terapêutico - Encontrarte: Viver arte, criar e recriar a vida. In S. Ciornai. Percursos em arteterapia (pp. 49-81). São Paulo: Summus.

Scharanck, G., \& Oischowski, A. (2008). O centro de atenção psicossocial e as estratégias de inserção da família. Revista Escola de Enfermagem da USP, 42(1), 127-134.

Winnicott, D. W. (1975). O brincar e a realidade. Rio de Janeiro: Imago.

Winnicott, D. W. (1982). A criança e seu mundo. Rio de Janeiro: LTC.

Winnicott, D. W. (1983). O ambiente e os processos de maturação: Estudos sobre a teoria do desenvolvimento emocional. (I. C. S. Ortiz, Trad.). Porto Alegre: Artes Médicas.

Winnicott, D. W. (2005). Tudo começa em casa. São Paulo: Martins Fontes.

Recebido: 10/05/2010

Received: 05/10/2010

Aprovado: 03/09/2010

Approved: 09/03/2010 